\title{
Penerapan model pembelajaran problem solving fisika berbantuan alat peraga kolektor surya pada pembelajaran kalor di SMA IT Iqra'
}

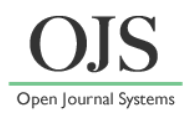

\author{
Rini Wulandari ${ }^{1 *}$, Eko Swistoro² ${ }^{2}$ M. Lutfi Firdaus ${ }^{1}$ \\ ${ }^{1}$ Pascasarjana Pendidikan IPA FKIP Universitas Bengkulu \\ ${ }^{2}$ Pendidikan Fiska FKIP Universitas Bengkulu \\ *Email : riniwulandari021290@gmail.com
}

DOI: https://doi.org/10.33369/pendipa.3.3.154-159

\begin{abstract}
[Application of Physics Problem Solving Learning Model Assisted Collector Solar Props on Heat Learning in SMA IT Iqra ']. The aims of this study is to explain the students 'cognitive learning outcomes using the learning model of Physics Solving Problem assisted solar collectors in heat learning in SMA IT Iqra' Bengkulu, and to explain the cognitive learning outcomes between high, medium and low group students. The subjects of this study are 24 students who follow the physical extracurricular activities in SMA IT Iqra 'Bengkulu. This type of research is pre-experimental by setting aside a group of pretest and posttest designs. Student cognitive learning result data obtained by test instrument that is question of multiple choice. Pretest measurement data form the basis for grouping students into high, medium and low groups. Data on cognitive learning outcomes were analyzed and calculated using normalized gain values and analyzed using the Anova test. The results showed that overall $N$-gain of 0.59 was moderate. $N$-gain based on group that is high group equal to 0,72; medium group of 0,58; and low group of 0.47. Based on anova test conducted to know the difference of cognitive learning result between student group obtained $F_{\text {count }}=4,046>F_{\text {table }} 3,47$ and sig value. $0.033<0.05$. The conclusion of this research is the learning model of Physics Solving Problem assisted by solar collector can improve students 'cognitive learning outcomes in extracurricular activities in SMA IT Iqra' Bengkulu and there is a significant difference of cognitive learning achievement among high, medium and low students.
\end{abstract}

Keywords: Learning model; Physics Problem Solving; Heat, Cognitive learning outcomes

(Received December 17, 2019; Accepted July 5, 2019; Published October 24, 2019)

\begin{abstract}
ABSTRAK
Penelitian ini bertujuan untuk menjelaskan peningkatan hasil belajar kognitif siswa yang diajarkan menggunakan model pembelajaran Problem Solving Fisika berbantuan alat peraga kolektor surya dalam pembelajaran kalor di SMA IT Iqra' Kota Bengkulu, dan untuk menjelaskan perbedaan peningkatan hasil belajar kognitif antara siswa kelompok tinggi, sedang dan rendah. Subjek penelitian ini adalah 24 siswa yang mengikuti kegiatan ekstrakurikuler fisika di SMA IT Iqra' Kota Bengkulu. Jenis penelitian adalah pre-eksperimental dengan desain one group pretest and posttest design. Data hasil belajar kognitif siswa diperoleh dengan instrumen tes yaitu soal pilihan ganda. Data hasil nilai pretest menjadi dasar pengelompokan siswa ke dalam kelompok tinggi, sedang dan rendah . Data hasil belajar kognitif dianalisis secara deskriptif dan dihitung dengan menggunakan skor gain yang dinormalisasi serta dianalisis menggunakan uji Anova. Hasil penelitian menunjukkan $\mathrm{N}$-gain keseluruhan siswa sebesar 0,59 berkategori sedang. $\mathrm{N}$-gain berdasarkan kelompok yaitu kelompok tinggi sebesar 0,72 ; kelompok sedang sebesar 0,58; dan kelompok rendah sebesar 0,47. Berdasarkan uji anova yang dilakukan untuk mengetahui perbedaan hasil belajar kognitif antar kelompok siswa diperoleh $F_{\text {hitung }} 4,046>F_{\text {tabel }} 3,47$ dan nilai sig. $0,033<0.05$. Kesimpulan penelitian ini adalah model pembelajaran Problem Solving Fisika berbantuan alat peraga kolektor surya dapat meningkatkan hasil belajar kognitif siswa pada kegiatan ekstrakurikuler di SMA IT Iqra' Kota Bengkulu dan terdapat perbedaan peningkatan hasil belajar kognitif yang signifikan antara siswa kelompok tinggi, sedang dan rendah.
\end{abstract}

Kata kunci: Model Pembelajaran; Problem Solving Fisika; Kalor, Hasil belajar kognitif. 


\section{PENDAHULUAN}

Pembelajaran kalor merupakan pembelajaran yang erat kaitannya dengan kehidupan sehari-hari. Permasalahan kalor sering muncul dalam berbagai keadaan. Bagi seorang siswa diperlukan suatu model pembelajaran untuk mengatasi hal tersebut. Diharapkan model pembelajaran problem solving fisika yang dikembangkan khusus untuk memecahkan masalah pembelajaran fisika dapat menjawab permasalahan tersebut.

Krulik dan Rudnick berpendapat bahwa problem soving ialah upaya individu atau kelompok untuk menemukan jawaban berdasarkan pengetahuan, pemahaman, keterampilan yang telah dimiliki sebelumnya dalam rangka memenuhi tuntutan situasi yang tak lumrah (Daryanto dan Karim, 2017). Pemecahan masalah termasuk seperangkat komponen kognitif, perilaku, dan sikap yang komplek (Kirkley, 2003). Aktifitas problem solving diawali dengan konfrontasi dan berakhir apabila sebuah jawaban telah diperoleh sesuai dengan kondisi masalah (Daryanto dan Karim 2017).

Langkah-langkah pembelajaran dengan model pembelajaran problem solving fisika ialah: 1). Memahami masalah secara umum, 2). Me-nampilkan masalah menurut aspek fisika, 3). Membuat suatu rencana pemecahan masalah, 4). menjalankan rencana 5). Evaluasi dan perluasan (Warimun, 2012). Pada langkah pembelajaran ke tiga yaitu rencana pemecahan masalah, guru dapat menyediakan alat peraga sebagai media bagi siswa untuk mendapatkan konsep yang akan digunakan dalam pemecahan masalah.

Penerapan model pembelajaran problem solving fisika yang dipadukan dengan alat peraga diharapkan dapat menambah keefektifan pembelajaran dan membuat pembelajaran kalor yang bersifat abstrak menjadi lebih konkrit sehingga dapat meningkatkan hasil belajar kognitif siswa. Kegiatan percobaan dengan menggunakan alat peraga juga akan memudahkan siswa untuk memahami materi yang bersifat abstrak menjadi konkrit (Wulandari dkk, 2018).

Alat peraga merupakan alat bantu pendidikan yang digunakan oleh pendidik dalam menyampaikan bahan pendidikan atau pengajaran (Kurniasih dan Sani 2017). Penggunaan alat peraga dalam pembelajaran sangat dianjurkan, karena dengan memanfaatkan alat peraga yang sesuai dengan materi, pembelajaran fisika akan lebih efektif dengan langsung memperagakan dan melakukan percobaan. Pembelajaran fisika yang dikenal siswa sebagai mata pelajaran yang rumit dan sukar dipelajari, akan menjadi lebih mudah dipahami, menyenangkan bagi siswa dan guru dapat lebih kreatif dalam menyampaikan materi pelajaran, dengan penggunaan alat peraga (Hamdani dkk, 2012).

Berdasarkan observasi terhadap guru fisika SMA IT Iqra' Kota Bengkulu didapatkan informasi bahwa metode pembelajaran yang digunakan guru pada pembelajaran kalor yaitu metode pembelajaran inkuiri di dalam kelas. Kegiatan demonstrasi dan eksperimen terbatas untuk dilakukan. Keterbatasan ini dikarenakan SMA IT Iqra' baru berdiri tahun 2013. Keterbatasan alat peraga dan alat KIT fisika di SMA ini menuntut guru mata pelajaran fisika untuk kreatif dalam menyediakan alat peraga. Kegiatan ektrakurikuler di SMA IT Iqra' Kota Bengkulu sudah cukup bagus, meskipun berada dalam keterbatasan. Hal ini terbukti dari prestasi yang diraih kegiataan ektrakurikuler fisika yaitu dapat meraih juara umum pada perlombaan POIF UNIB Tahun 2015 (User, 2015).

Oleh sebab itu peneliti tertarik melakukan penelitian dengan model pembelajaran problem solving fisika berbantu alat peraga kolektor surya pada pembelajaran kalor sehingga diharapkan dapat meningkatkan pemahaman konsep mereka terhadap bahasan tersebut. Tujuan dari penelitian ini adalah untuk menjelaskan peningkatan hasil belajar kognitif siswa yang diajarkan menggunakan model pembelajaran Problem Solving Fisika berbantu alat peraga kolektor surya dalam pembelajaran kalor pada kegiatan ektrakulikuler di SMA IT Iqra' Kota Bengkulu, dan untuk menjelaskan perbedaan peningkatan hasil belajar kognitif antara siswa kelompok tinggi, sedang dan rendah.

\section{METODE PENELITIAN}

Penelitian ini telah dilaksanakan pada bulan April - Mei 2018. Subjek penelitian adalah 24 siswa yang mengikuti kegiatan ektrakulikuler fisika di SMA IT Iqra' Kota Bengkulu. Jenis penelitian ini adalah pre-experimental dengan 
desain one group pretest and posttest design (Sugiyono, 2017). Desain tersebut dapat dilihat pada tabel 1 di bawah ini.

Tabel 1. Desain Penelitian pre-experimental

\begin{tabular}{c|c|c}
\hline Pre-Test & Variabel & Post-Test \\
\hline $\mathrm{O}_{1}$ & $\mathrm{X}$ & $\mathrm{O}_{2}$ \\
\hline
\end{tabular}

Keterangan :

$\mathrm{X}=$ ada perlakuan ( Model pembelajaran

Problem solving fisika menggunakan alat peraga kolektor surya)

$\mathrm{O}_{1}=$ nilai pre-test (sebelum diberi perlakuan)

$\mathrm{O}_{2}=$ niali post-test (setelah diberi perlakuan)

Teknik pengumpulan data penelitian ini adalah observasi dengan instrumen tes penilaian hasil belajar kognitif berupa soal pilihan ganda. Instrumen tersebut dilakukan uji panelis dan uji coba kepada siswa yang sudah pernah mengikuti pembelajaran kalor. Pengolahan data menggunaan program SPSS versi 20 (Arifin, 2017). Teknik analisis data menggunakan analisis $\mathrm{N}$ gain untuk mengetahui peningkatan hasil belajar kognitif siswa. N-gain adalah skor gain yang dinormalisasi dengan menggunakan rumus gfaktor

$$
g=\frac{(\text { Spost }- \text { Spre })}{(\text { Smax }- \text { Spre })}
$$

dimana g adalah gain yang dinormalisasi, Smax adalah skor maksimum (ideal) dari tes awal dan tes akhir, Spost adalah skor tes akhir, sedangkan Spre adalah skor tes awal. Tinggi rendahnya skor gain yang dinormalisasi (N-gain) dapat diklasifikasikan dalam tiga kategori, yaitu: $\mathrm{N}$ gain $>0,7$ kategori tinggi, $0,3 \leq \mathrm{N}$-gain $\leq 0,7$ kategori sedang, $\mathrm{N}$-gain $<0,3$ berkategori rendah (Warimun, 2012).

Analisis Anova satu jalur (one way anova) digunakan aplikasi SPSS versi 20. Analisis anova digunakan untuk mengetahui perbedaan peningkatan hasil belajar pada kelompok tinggi, sedang dan rendah. Hipotesis dalam uji anova ini adalah :

$\mathrm{H}_{0}=$ Tidak terdapat perbedaan peningkatan hasil belajar kognitif yang signifikan antara siswa kelompok tinggi, sedang dan rendah $\mathrm{H}_{1}=$ Terdapat perbedaan peningkatan hasil belajar kognitif yang signifikan antara siswa kelompok tinggi, sedang dan rendah.

\section{HASIL DAN PEMBAHASAN}

Instrumen tes berupa soal pilihan ganda sebanyak 15 butir soal dinyatakan valid dan reliabel dari uji panelis oleh tiga orang ahli dengan analisi anova hoyt $\left(\mathrm{r}_{11}\right)$ sebesar 0,68 dengan kategori sangat tinggi. Selanjutnya hasil uji coba kepada siswa yang telah mengikuti pembelajaran kalor didapatkan hasil 10 butir soal dinyatakan valid, reliabel, daya pembedanya baik, dan taraf kesukatannya baik setelah dilakukan pengujian. Selanjutnya intrumen tes tersebut digunakan untuk mengumpulkan data hasil belajar kognitif siswa.

Penelitian yang dilakukan dengan menerapkan model pembelajaran problem solving fisika diawali dengan mengelompokkan siswa ke dalam kelompok tinggi sedang dan rendah berdasarkan nilai pretest yang mereka peroleh. Nilai pretes merupakan tingkatan kemampuan awal yang dimiliki siswa.

Tabel 2. Data pengelompokkan siswa

\begin{tabular}{c|c|c|c|c}
\hline No. & Nilai pretes & $\begin{array}{c}\text { Banyak } \\
\text { siswa }\end{array}$ & $\begin{array}{c}\text { Persen- } \\
\text { tase }\end{array}$ & Kategori \\
\hline 1. & $\geq 70$ & 6 & $25 \%$ & Tinggi \\
\hline 2. & $50 \leq$ nilai $<70$ & 12 & $50 \%$ & Sedang \\
\hline 3. & $<50$ & 6 & $25 \%$ & Rendah \\
\hline \multicolumn{4}{|c}{ Berdasarkan tabel 2 }
\end{tabular}

pengetahuan awal sebanyak $50 \%$ siswa di kelas penelitian termasuk dalam kelompok sedang, dan sisanya $25 \%$ dalam kelompok tinggi dan $25 \%$ dalam kelompok rendah.

Kegiatan yang dilakukan selanjutnya yaitu pembelajaran dengan menggunakan model pembelajaran problem solving fisika. Pada pembelajaran ini siswa diberikan sebuah permasalahan yang harus dipecahkan. Siswa harus menemukan konsep kalor dari kegiatan demonstrasi menggunaan alat peraga kolektor surya untuk memecahkan masalah tersebut. Alat peraga kolektor surya yang digunakan dapat dilihat pada Gambar 1 di bawah ini. 


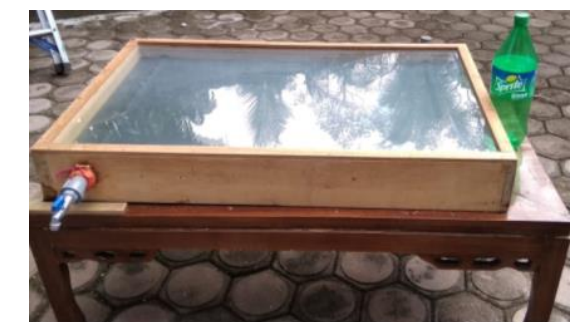

Gambar 1. Alat peraga kolektor surya pemanas air

Alat peraga kolektor surya pemanas air pada Gambar 1 di atas, digunakan pada saat proses pembelajaran untuk menemukan konsep kalor. Hasil belajar kognitif setelah dilakukan pembelajaran dengan model pembelajaran problem solving fisika menggunakan alat peraga tersebut dapat dilihat pada tabel 3 di bawah ini.

Tabel 3. Data hasil nilai rata-rata pretest dan posttest

\begin{tabular}{r|l|r|r|r|r|r|r}
\hline \multirow{2}{*}{ No. } & \multirow{2}{*}{$\begin{array}{c}\text { Kelompok } \\
\text { Siswa }\end{array}$} & $\begin{array}{c}\text { Pre- } \\
\text { test }\end{array}$ & SD & $\begin{array}{c}\text { Post- } \\
\text { test }\end{array}$ & SD & Gain & SD \\
\hline 1. & Tinggi & 76.67 & 5.16 & 93.33 & 5.16 & 16.67 & 5.1 \\
\hline 2. & Sedang & 57.50 & 4.52 & 82.50 & 4.52 & 25,00 & 6.7 \\
\hline 3. & Rendah & 40,00 & 0 & 68.33 & 7.52 & 28.33 & 7.5 \\
\hline 4. & $\begin{array}{l}\text { Keseluruh } \\
\text { an }\end{array}$ & 57.92 & 13.82 & 81.67 & 10.5 & 23.75 & 7.7 \\
\hline
\end{tabular}

Berdasarkan Tabel 3 di atas terlihat bahwa nilai rata-rata pretest kelompok tinggi sebesar 76,67 dan posttest nya sebesar 93.33 , nilai ratarata pretest kelompok sedang sebesar 57,50 dan posttest nya sebesar 82,50 , dan nilai rata-rata pretest kelompok rendah sebesar 40,00 dan posttest nya sebesar 68,33 . Rata-rata gain kelompok tinggi yaitu 16,67; kelompok sedang yaitu 25,00; dan kelompok rendah yaitu 28,33. Peningkatan hasil belajar kelompok dapat dilihat dari Tabel 4 di bawah ini.

Tabel 4. N-gain rata-rata

\begin{tabular}{|c|c|c|c|}
\hline \multirow[b]{2}{*}{ No } & \multirow{2}{*}{$\begin{array}{l}\text { Kelompok } \\
\text { Siswa }\end{array}$} & \multicolumn{2}{|c|}{ Hasil Belajar Kognitif } \\
\hline & & $\begin{array}{l}\text { N-gain } \\
\text { rata-rata }\end{array}$ & $\begin{array}{c}\text { Kategori } \\
\text { N-gain }\end{array}$ \\
\hline 1 & Tinggi & 0.72 & Tinggi \\
\hline 2 & Sedang & 0.58 & Sedang \\
\hline 3 & Rendah & 0.47 & Sedang \\
\hline 4. & Keseluruhan & 0,59 & Sedang \\
\hline
\end{tabular}

Berdasarkan Tabel 4, terlihat hasil belajar kognitif yang diwakili oleh nilai $\mathrm{N}$-gain ratarata. $\mathrm{N}$-gain adalah nilai gain yang dinormalisasi. N-gain rata-rata kelompok siswa tinggi sebesar 0,72 sehingga dikategorikan tinggi, kemudian $\mathrm{N}$-gain rata-rata kelompok siswa sedang sebesar 0,58 sehingga dikategorikan sedang, serta $\mathrm{N}$-gain rata-rata kelompok siswa rendah sebesar 0,47 sehingga dikategorikan sedang. Keseluruhan peningkatan hasil belajar kognitif siswa sebesar 0,59 atau 59\% dengan kategori sedang. Artinya setelah dilakukan pembelajaran dengan model pembelajaran Problem Solving Fisika berbantu alat peraga kolektor surya pada pembelajaran kalor pengetahuan kognitif siswa meningkat sebesar 59\% dari pengetahuan awalnya.

Diagram batang nilai pretes dan posttest dapat dilihat dari Gambar 2.

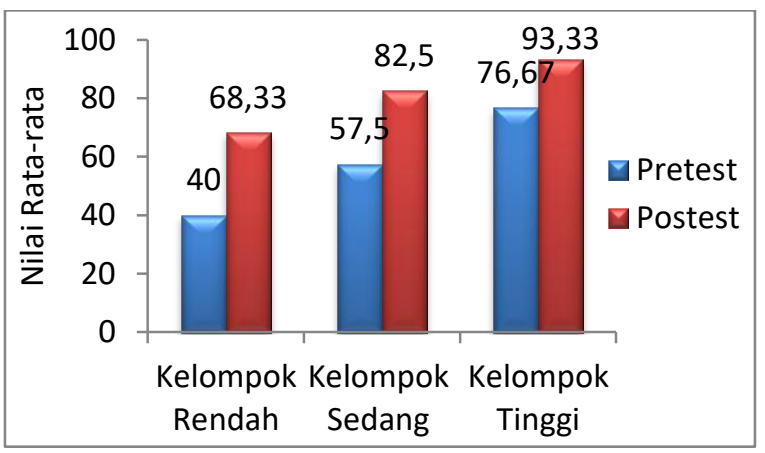

Gambar 2. Grafik nilai rata-rata pretest dan posttest

Peningkatan hasil belajar kognitif antara siswa kelompok tinggi, sedang, dan rendah dapat tergambar dari Gambar 3 di bawah ini.

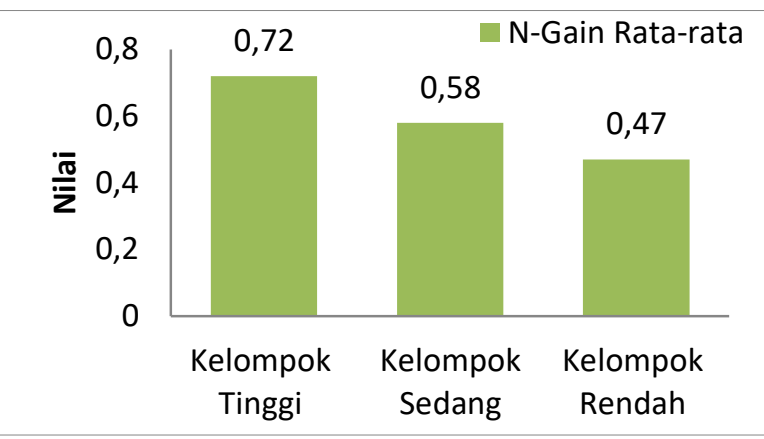

Gambar 3. Grafik N-gain rata-rata (peningkatan hasil belajar kognitif siswa) 
Berdasarkan Gambar 3 di atas terlihat adanya peningkatan hasil belajar kognitif antara siswa kelompok tinggi sebesar 0,72 , kelompok sedang 0,58 dan kelompok rendah sebesar 0,47.

Uji Anova satu jalur (one way anova) dilakukan untuk mengetahui apakah ada perbedaan peningkatan hasil belajar kognitif antara siswa kelompok tinggi, sedang dan rendah.

Uji homogenitas data hasil belajar kognitif yang digunakan adalah Uji Homogenitas Levene. Adapun hasil Uji Homogenitas Levene data hasil belajar kognitif adalah seperti Tabel 5 berikut.

Tabel 5. Test of Homogeneity of Variances

\begin{tabular}{r|r|r|rr}
\multicolumn{1}{l}{ N_gain } \\
$\begin{array}{c}\text { Levene } \\
\text { Statistic }\end{array}$ & df1 & df2 & \multicolumn{2}{|c}{ Sig. } \\
\hline 3.188 & 2 & 21 & .062 \\
\hline
\end{tabular}

Berdasarkan Tabel 5 di atas, terlihat bahwa nilai Sig. $0.062>0,05$. Nilai tersebut bermakna bahwa varians data sama (homogen). Hasil uji anava dapat dilihat pada Tabel 6 di bawah ini.

Tabel 6. ANOVA

N_gain

\begin{tabular}{l|r|r|r|r|r}
\hline & $\begin{array}{c}\text { Sum of } \\
\text { Squares }\end{array}$ & Df & $\begin{array}{c}\text { Mean } \\
\text { Square }\end{array}$ & F & Sig. \\
\hline $\begin{array}{l}\text { Between } \\
\text { Groups }\end{array}$ & .189 & 2 & .094 & 4.046 & .033 \\
Within & .490 & 21 & .023 & & \\
Groups & .678 & 23 & & & \\
Total & & & & \\
\hline
\end{tabular}

Berdasarkan Tabel 6 di atas, terlihat bahwa dari hasil uji Anova nilai F hitung 4,046> F tabel sebesar 3.47 dan nilai sig. $0,033<0,05$, maka $\mathrm{H}_{0}$ ditolak dan $\mathrm{Ha}$ diterima. Artinya dalam penelitian ini terdapat perbedaan peningkatan hasil belajar kognitif yang signifikan antara siswa kelompok tinggi, sedang dan rendah.

Hasil penelitian yang memadukan model pembelajaran dengan alat peraga ini sejalan dengan hasil penelitian sebelumnya. Hasil penelitian Wulandari dkk (2018) adalah peningkatan dan perbedaan hasil belajar kelas eksperimen dan kelas kontrol dipengaruhi oleh beberapa faktor diantaranya penerapan model pembelajaran oleh guru dan penggunaan media atau alat peraga

Hasil penelitian ini sejalan dengan penelitian yang dilakukan penelitian sebelumnya yang dilakukan Warimun (2012) tentang penerapan model pembelajaran problem solving fisika pada pembelajaran topik optika pada mahasiswa menyimpulkan bahwa pembelajaran dengan menggunakan model pembelajaran problem solving dapat meningkatkan penguasaan konsep fisika dalam topik optika geometri dan kemampuan problem solving mahasiswa dalam optika geometri dengan kategori tinggi. Hasil penelitian ini juga sejalan dengan penelitian Indrayana dkk (2015) berjudul pengaruh model problem solving dan scaffolding terhadap pemahaman konsep fisika siswa kelas XI IPA dimana hasil kesimpulan pertamanya bahwa terdapat pengaruh model pembelajaran (problem solving dan konvensional) terhadap pencapaian pemahaman konsep siswa.

\section{KESIMPULAN}

Berdasarkan penelitian yang telah dilakukan diperoleh kesimpulan bahwa model pembelajaran Problem Solving Fisika berbantuan alat peraga kolektor surya dapat meningkatkan hasil belajar kognitif siswa pada kegiatan ekstrakurikuler di SMA IT Iqra' Kota Bengkulu sebesar 59\% dengan kategori sedang. Peningkatan hasil belajar kognitiif siswa berdasarkan kelompoknya yaitu kelompok tinggi sebesar 0,72 kategori tinggi, siswa kelompok sedang sebesar 0,58 kategori sedang, dan siswa kelompok rendah sebesar 0,47 kategori sedang. Terdapat perbedaan peningkatan hasil belajar kognitif yang signifikan antara siswa kelompok tinggi dan rendah. Hal ini terlihat dari $\mathrm{F}$ hitung 4,046 > F tabel sebesar 3.47 dan nilai sig. 0,033 $<0,05$.

\section{DAFTAR PUSTAKA}

Arifin J. (2017) SPSS24 untuk Penelitian dan Skripsi. Jakarta: Elex Media Komputindo.

Daryanto. dan Karim, S. (2017) Pembelajaran Abad 21 (pp.33). Yogyakarta: Gava Media.

Hamdani D., Kurniati E., Sakti, I. (2012) Pengaruh Model Pembelajaran Generatif dengan Menggunakan Alat Peraga terhadap Pemahaman Konsep Cahaya 
Kelas VIII di SMP Negeri 7 Kota Bengkulu, Jurnal Exacta, 79(1), 14123617.

Indrayana, I.P.T., Santyasa, W.I., Artawan, P. (2015) Pengaruh Model Problem Solving dan Scaffolding Terhadap Pemahaman Konsep Fisika Siswa Kelas XI IPA, Prosiding Pertemuan Ilmiah XXIX HFI Jateng dan DIY, 0853-0823.

Kirkley, J. (2003) Principles for Teaching Problem Solving (pp.5). Indiana University : PLATO Learning, Inc.

Kurniasih, I. dan Sani, B. (2017) Lebih Memahami Konsep \& Proses Pembelajaran Implementasi \& Praktek Dalam Kelas (p.23). Jakarta : Kata Pena.

Sugiono. (2017) Metode Penelitian Kuantitatif, Kualitatif, dan $R \& D$ (pp.74). Bandung : Alfabeta.

User, S. 2015. Prestasi 1,5 tahun SMA IT IQRA Kota Bengkulu. Diambil dari http://www.smaitiqrabengkulu.sch.id

Warimun, E.S. (2012) Pengembangan Model Pembelajaran Problem Solving melalui Pembelajaran Topik Optika pada Mahasiswa Pedidikan Fisika. Jurnal Exacta X(2) pp.111-114, 1412-3617.

Wulandari, D.W., Swistoro, E., Conie. (2018) Efektivitas Sphygmomanometer Aneroid Modifikasi sebagai Alat Ukur Tekanan Hidrostatis dan Implementasinya sebagai Alat Peraga. Jurnal PENDIPA 2(1) pp.8287, 2086-9363. 